\title{
Layer Stiffness Moduli Measured by Light Weight Deflectometer Tests and Predicted by Backcalculation Process for Sandy Soil
}

\author{
Dr. Dina Kuttah \\ The Swedish National Road and Transport Research Institute, VTI \\ (SE-58195 Linköping, Sweden) \\ E-mail: dina.kuttah@vti.se
}

\begin{abstract}
Construction of roads involves the design, construction and quality controls of roads which ususlly based on collected or estimated road layers parameters. In this contest, it has become interesting to correlate testing parameters collected by simple tests to be used in Mechanistic-Empirical Pavement Design software. The current research has focused on determining the deflection basins and material stiffnesses from simple, cheap and time saving field test such as the light weight deflectometers (LWD). To reach this goal different field LWD have been carried out on compacted sandy subgrade soil at different moisture contents and applied dynamic loads. In addition, field moisture contents and material characterizing laboratory tests have been carried out. The layer stiffness moduli were also predicted using backcalculation process based on Multi-Layer Elastic Theory (MLET) and compared with dynamic deformation moduli measured by LWD for judging stiffnesses. The tests results showed that the percent difference between the stiffnesses measured by LWD and the stiffnesses predicted by backcalculation process increased with increasing the moisture contents and the applied loads. A minimum percent difference of 3.5\% between the measured and predicted stiffness were reported for points loaded with lowest falling weight of $3 \mathrm{kN}$ and tested at lowest water content of $3 \%$. For heaviest tested falling weight of $7 \mathrm{kN}$ and highest tested moisture contents of $9 \%$, the calculated and predicted stiffnesses were mismatched recording $21 \%$ percent difference.
\end{abstract}

Keywords: Deflection basin, Layer stiffness moduli, Light weight deflectometer and Sandy soil.

\section{Introduction}

The calculations of important parameters for the pavement design purposes, in the mechanistic method, concerns the estimation of the Young's modulus E and Poisson ratio $v$. The resilient modulus (Mr) is a stiffness measurement of pavement layers and defined as the unloading modulus of the hysteresis loop after many cycles of repeating loads usually collected by repeated load triaxial (RLT) tests. In fact, the resilient modulus tests of road materials are relatively expensive and time consuming. Therefore, the development of a simple and reliable alternative testing technique for Mr is desirable [1-3]. As a result, many of the pavement design standards are based on materials properties evaluated using simpler and faster tests such as the static plate loading test, static CBR, and others [4]. In spite of the fact that these static tests are very common all over the world, but they are not correlated efficiently to the dynamic response of the pavement structure under the actual traffic loading of moving vehicles. The falling weight deflectometer (FWD) tests have been used in the evaluation of material properties of pavement system for decades [5]. The FWD applies impulsive load to a pavement surface and the deflection response is recorded at a series of radial point. The load amplitudes and frequency content intend to provide pavement deformation levels similar to those induced by truck wheal loads in heavy urban traffic loading and it can also produce a huge amount of deflection data in a short period of time [6]. The evaluation of the FWD data requires the inversion of mechanical pavement properties using a backcalculation tool that includes both a forward pavement response model and an optimization algorithm. In order to reduce further the testing time and the effort spent in running the FWD tests, this test has been replaced by a light weight deflectometer test (LWD). The LWD theory and the measured modulus have been discussed in several studies [7-9]. In this study, the data collected from the LWD test were analyzed using the Multi-Layer Elastic Theory backcalculated program in order to find the layer structural capacity and to evaluate the changes in the tested layer deformation moduli for different moisture contents and applied impulsive loads. 


\section{Selected Material Properties}

Commonly available sandy subgrade soil has been selected to be tested in this study. The particle size distribution of the tested soil is illustrated in Table 1 below:

Table 1: Particle size distribution of the tested sandy soil.

\begin{tabular}{|c|c|c|c|c|c|c|c|}
\hline Sieve & 4 & 2 & 1 & 0.5 & 0.25 & 0.125 & 0.063 \\
\hline \% finer than & 100 & 100 & 98 & 69 & 27 & 8 & 2.2 \\
\hline
\end{tabular}

The tested soil is a SP sand (poorly graded sand) according to ASTM D-2487 [10].

The specific gravity of the selected sandy soil was tested according to SS-EN 1097-6 [11] and it was found to be 2.664.

In this test, the compaction properties were determined by modified Proctor test as per ASTM D1557 [12]. The test was performed by compacting several soil samples using a cylindrical mold of $152.4 \mathrm{~mm}$ diameter. The results of a set of modified Proctor compaction tests on the selected sandy soil gave a maximum dry density of $1.72 \mathrm{~g} / \mathrm{cm}^{3}$ at an optimum moisture content of $12 \%$.

\section{Field Testing}

The field LWD and moisture content tests have been conducted on a large test pit of the compacted material under controlled conditions. The test pit was approximately $9.5 \mathrm{~m}$ long x $5 \mathrm{~m}$ width $\mathrm{x} 1.5 \mathrm{~m}$ depth and equipped with a concrete well with a water discharging motor that was used to control the ground water level during testing, as shown in Figure 1 (A).

When the compaction completed, the final sandy surface was marked with circles representing the selected places of the points to be tested, see Figure 1 (B).

\section{Equipment Used and Working Principles}

\subsection{Light Weigh Deflectometer (LWD) Test}

The Light Weight Deflectometer (LWD) is a modulus-based measurement tool that has significant potential for use as part of the compaction control process [13]. It measures the deflection from a falling weight to estimates the dynamic deformation modulus (Evd). The Evd is calculated using the elastic half-space theory for one-layer system based on Boussinesq theory [14], see Eq. (1). This equation assumes the test media to be a linearly elastic, isotropic, homogeneous semi-infinite continuum. Two of the parameters required for determining the modulus, the shape factor for distribution of the contact stress between the plate and the soil (A) and Poisson's ratio (v), are assumed.

$$
\mathrm{E}=2 \mathrm{k}\left(1-v^{2}\right) / \mathrm{Ar}_{\mathrm{o}}
$$

where, $\mathrm{k}=\mathrm{load}$ (peak)/deformation (peak), $\mathrm{r}_{\mathrm{o}}=$ the plate radius, $\mathrm{A}=$ stress distribution factor and $\nu=$ Poisson's ratio

The light weight deflectometer working principle is based on measuring the deflection induced by dropping weight of up to $20 \mathrm{~kg}$ and detected by built-in geophones, see Figure $1 \mathrm{C}$. 

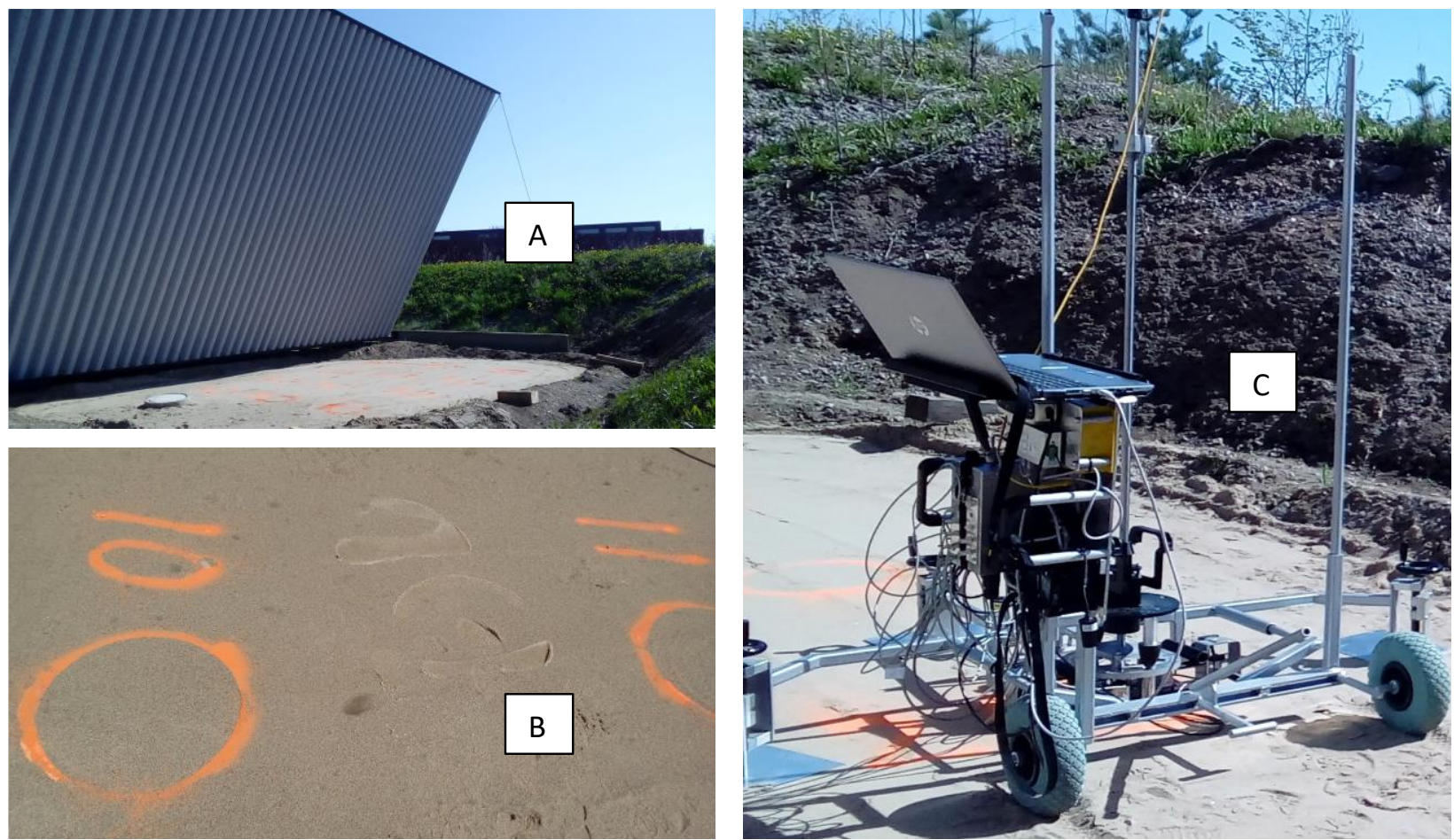

Fig. 1: (A) Compacted final surface in the test pit, (B) Marking the points to be tested and (C) KUAB LWD used in the study.

The used LWD has a basic $10 \mathrm{~kg}$ falling mass. During the test, the falling mass impacts the plate, producing a load pulse of up to $7 \mathrm{kN}$ depending on the falling height. The centre deflection of the tested material surface is measured through a hole in the loading plate by a highly accurate, seismic transducer (geophone). Two more deflection geophones have been added at $30 \mathrm{~cm}$ and $60 \mathrm{~cm}$ from the loading centreline. The basic diameter of the loading plate used in this study was $300 \mathrm{~mm}$ during field measurements. The drop height can be easily and quickly adjusted by a movable release handle and the peak value of the impact force is based on actual measurements from the load cell, see Figure $1 \mathrm{C}$.

The data collection software is installed in PC coupled to the LWD. The deformation modulus of the surface and/or plate (Evd) in addition to time history graph from both the deflection sensors and the load sensor can be displayed in the PC screen in real time. For LWD at field, the Evd is calculated using eq. 1 and assuming, $A=4$ and $v=0.35$.

Furthermore, the deformation moduli measured by field LWD at $30 \mathrm{~cm}$ and $60 \mathrm{~cm}$ from the drop load centreline were calculated based on Eq. (2) for stresses at eccentricity from the load centreline. The dynamic deflection of the subgrade and/or base material is determined by considering that the media is a semi-infinite elastic body and the loading is uniform over a circular area. This can be mathematically calculated as:

$$
\text { Evd field }=F^{*}(1-v 2) /(\pi . r . d r)
$$

where, $\mathrm{dr}=$ deflection at distance $\mathrm{r}$ from the center and $\mathrm{F}=$ peak force.

\subsection{Nuclear Density Gauge (NDG)}

The Nuclear Density Gauge (NDG) was used to determine the in-situ moisture content of the tested soil in the test pit. The test method is useful as a rapid, nondestructive technique for in-place measurements of wet density and water content of soil and soil-aggregate and the determination of dry density [15]. 


\section{Results and Discussion}

Different points under relatively low moisture contents (about 3\%) and higher moisture contents of about 9\% (after watering) have been tested using a multifunctional LWD developed by KUAD AB.

The field LWD tests were carried out at three different drop loads by changing the drop height of $10 \mathrm{~kg}$ drop weight, to resulted in namely $3 \mathrm{kN}, 5 \mathrm{kN}$ and $7 \mathrm{kN}$ drop loads corresponding to $45 \mathrm{kPa}, 70 \mathrm{kPa}$ and $100 \mathrm{kPa}$ vertical contact pressure respectively.

Falling weight deflectometer (FWD) testing software has been used to evaluate the structural condition of pavements to predict the layer moduli using backcalculation process based on deflection data measured by LWD tests.

A comparison of the average dynamic deformations of similar tested points at the surface of the sandy subgrade layer using field LWD and backcalculation process based on Multi-Layer Elastic Theory (MLET) is illustrated in Figure 2 for different moisture content and loading conditions.

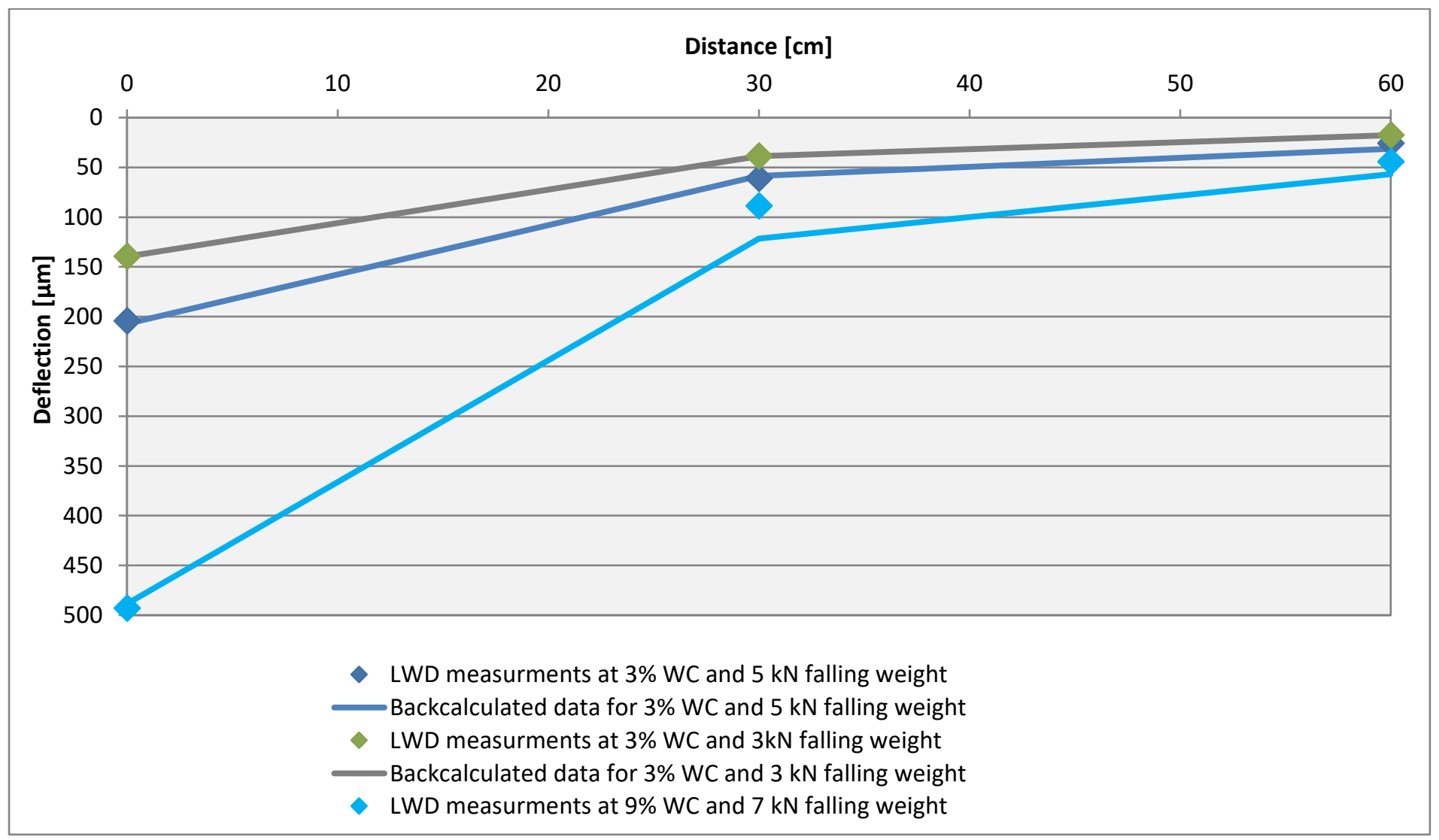

Fig. 2: Measured and back-calculated dynamic deflection basin for points tested at 3, 5 and $7 \mathrm{kN}$ falling weight at different moisture contents.

Note that MLET uses the data of falling weight deflectometer tests based on the second drop. During the routine LWD measurements, the average dynamic deformation modules for the last three drops after the first three pre-test drops usually considered (i.e. the Evd is taken to be the average for the Evds measured for drops 4, 5 and 6). The average Evd recorded for drops 4 to 6 have been adopted in the comparison presented in this study. In Figure 2, it can be seen that the influence lines for surface deformation at the top of the soil using backcalculation process match very well the measured total deflections using field LWD for points tested at low moisture contents of about 3\% and relatively low dropping weights of 3 and $5 \mathrm{kN}$. For points tested at higher moisture contents of $9 \%$ and heaviest drop weight of $7 \mathrm{kN}$, it can be 
seen that the backcalculated deflections diverse slightly from the corresponding deflections measured by field LWD, but the differences are still within the acceptable limits.

Regarding the layer stiffness, it can be seen from Figure 3 that the backcalculated layer stiffnesses are reasonably close to the corresponding dynamic deformation modulus measured by field LWD tests. It has been found that the percent difference between the stiffnesses measured by LWD and the stiffnesses predicted by backcalculation process increased with increasing the moisture contents and the applied loads. A minimum percent difference of $3.5 \%$ between the measured and predicted stiffness were reported for points loaded with lowest weight of $3 \mathrm{kN}$ and tested at lowest water content of $3 \%$. On the other hand, a maximum percent difference of $21.3 \%$ between the measured and predicted stiffness were reported for points loaded with heaviest weight of $7 \mathrm{kN}$ and tested at highest water content of $9 \%$.

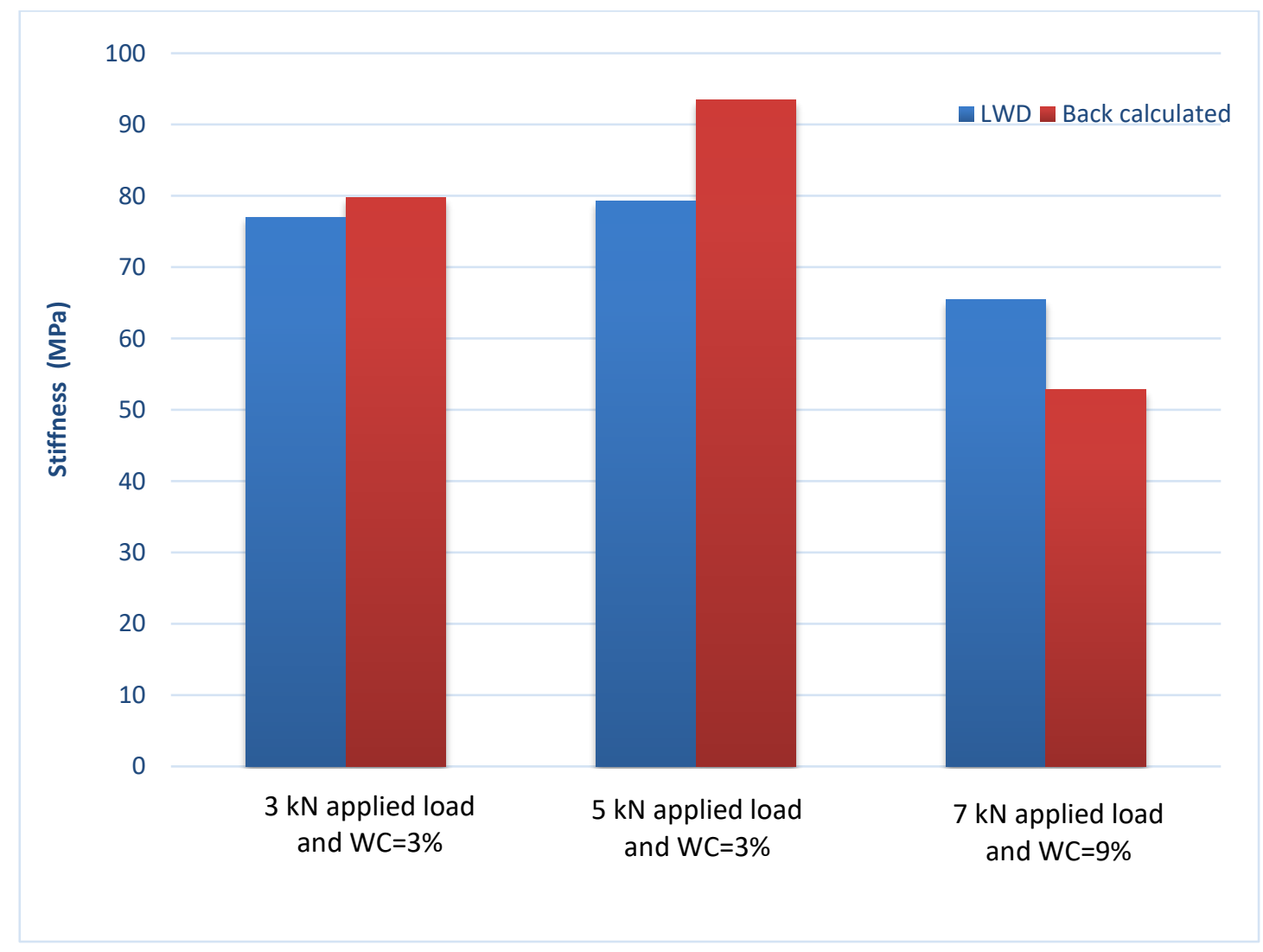

Fig. 3: Measured and back-calculated layer stiffnesses vs dynamic deflection moduli measured by LWD test for different falling weights and moisture contents.

\section{Conclusions}

The main objective of this study has been to verify the validity of estimating the dynamic properties of selected sandy subgrade soil using LWD instead of determining the dynamic materials properties from large scale tests, namely, the falling weight deflectometer test (FWD). The LWD tests have been performed at different moisture contents and various applied dynamic loads on a compacted sandy soil at a pre-constructed test pit. The deflection basins and compacted layer stiffnesses have been measured by field LWD and also predicted by backcalculated process based on Multi-Layer Elastic Theory (MLET). It has been found that the deflection basins and the compacted layer stiffnesses measured by LWD have matched best the predicted data from backcalculation process for the points tested at lowest moisture contents and falling drops 
weights. For highest moisture contents of $9 \%$ and heaviest falling weight of $7 \mathrm{kN}$, the calculated and predicted stiffnesses were mismatched recording $21 \%$ percent difference.

\section{Acknowledgements}

The author would like to express her gratitude to the Swedish Transport Administration for the financial grant via BVFF program for research, development and innovations in road and railway construction and maintenance. Special thank is extended to KUAB consult and development company for the manufacturing of the LWD used in this study.

\section{References}

[1] Pericleous, M. I. and Metcalf, J. B. "Resilient Modulus of Cement-Stabilized Phosphogypsum", Proceeding of the American Society of Civil Engineers, ASCE, Material Engineering Journal, Vol. 8, No.1, pp. 7-10, 1996.

[2] Kim, D; Kweon, G. and Lee, K., "Alternative Method of Determining Resilient Modulus of Subgrade Soils Using a Static Triaxial Test”, Canadian Geotechnical Journal, Vol. 38, No. 1, pp.107-116, 2001.

[3] Razouki, S. S. and Kuttah, D. K., "Effect of Soaking Period and Surcharge Load on Resilient Modulus and California Bearing Ratio of Gypsiferous soils", Quarterly Journal of Engineering Geology and Hydrogeology, London, Vol. 37, pp. 155-164, 2004. http://qjegh.geoscienceworld.org/content/37/2/155.abstract.

[4] Araya, A. A.; Huurman, Molenaar, A.A. and Houben L.J.M., "Investigation of the resilient behavior of granular base materials with simple test apparatus". Materials and Structures 45, pp. 695-705, 2012.

[5] Nega, A.; Nikaz, H. and Al-Qadi, I., "Dynamic analysis of falling weight deflectometer", Journal of Traffic and Transportation Engineering (English Edition) Volume 3, Issue 5, Pages 427-437, 2016. https://doi.org/10.1016/j.jtte.2016.09.010

[6] A. Bianchini, P. Bandini "Prediction of pavement performance through Neuro-Fuzzy reasoning Computer-Aided Civil and Infrastructure Engineering, 25 (1) (2010), pp. 39-54, 2010.

[7] Fleming P. R., Lambert J. P., Frost, M. W. and Rogers, C., "In-situ assessment of stiffness modulus for highway foundations during construction". Proceedings of the 9th International Conference on Asphalt Pavements, Copenhagen, Denmark, CD-ROM., 2002.

[8] White, D. J., Tompson, M. and Vennapusa, P., "Field Validation of Intelligent Compaction Monitoring Technology for Unbound Materials." Minnesota Department of Transportation, St Paul, MN, USA, Final Report, MN/RC- 200710., 2007.

[9] Mooney, M. A. and Miller, P. K., "Analysis of lightweight deflectometer test based on in situ stress and strain response". Journal of Geotechnical and Geo-environmental Engineering 135, No. 2, pp. 199-209, 2009.

[10] ASTM D2487 "Standard Practice for Classification of Soils for Engineering Purposes (Unified Soil Classification System)”. ASTM International, West Conshohocken, PA, United States, 2017.

[11] SS-EN 1097-6 "Tests for mechanical and physical properties of aggregates", Part 6 "Determination of particle density and water absorption", SIS, Swedish Standards Institute, Stockholm, Sweden, 2013.

[12] ASTM D1557 "Standard test methods for laboratory compaction characteristics of soil using modified effort (56,000 ft-lbf/ft3-2,700 kN-m/m3)", ASTM International, West Conshohocken, PA, United States, 2012.

[13] Fleming, P. R., Frost, M. W., and Lambert, J. P., "A review of the lightweight deflectometer (LWD) for routine in-situ assessment of pavement material stiffness." Transportation Research Record: Journal of the Transportation Research Board Volume: 2004 issue: 1, pages: 80-87, 2007.

[14] Boussinesq, M. J., “Application des potentiels a l'étude de l'équilibre et du mouvement des solides élastiques, avec des notes étendues sur divers points de physique mathématique et d'analyse", Paris: Gauthier-Villard imprimeur libraire, 1885.

[15] ASTM D6938 "Standard Test Methods for In-Place Density and Water Content of Soil and Soil-Aggregate by Nuclear Methods (Shallow Depth)," ASTM International, West Conshohocken, PA, 2017. [Online]. Available: http://www.astm.org. 